\title{
A Case of Reye Syndrome Caused by Influenza A Virus
}

\author{
Abdullah Noor, BA, ${ }^{1}$ Eleanor Gradidge, MD ${ }^{1,2}$ \\ ${ }^{1}$ The University of Queensland School of Medicine, Ochsner Clinical School, New Orleans, LA ${ }^{2}$ Department of Pediatrics, Ochsner Clinic \\ Foundation, New Orleans, LA
}

Background: Reye syndrome is a rare and potentially life-threatening disease characterized by liver failure and hepatic encephalopathy. Multiple possible etiologies have been suggested, but only aspirin (acetylsalicylic acid) has been statistically proven to be a causative factor. We describe a case of Reye syndrome secondary to influenza A virus.

Case Report: A 2-year-old male with a recent history of influenza-like symptoms presented with neurologic deterioration. He had elevated liver enzymes, hyperammonemia, elevated creatinine, and hypoglycemia. Liver biopsy showed microvesicular steatosis consistent with Reye syndrome. He was given supportive care and recovered after 17 days with normalization of metabolic derangements. At 4-month follow-up, the patient had reached age-specific developmental milestones.

Conclusion: The incidence of Reye syndrome has decreased since 1980 when the Centers for Disease Control and Prevention issued a warning against aspirin use in children. Consequently, any new incidence of Reye syndrome warrants investigation of other etiologies. This case adds to the evidence that causes other than aspirin can result in Reye syndrome.

Keywords: Hepatic encephalopathy, influenza A, Reye syndrome

Address correspondence to Eleanor Gradidge, MD, Department of Pediatrics, Ochsner Clinic Foundation, 1514 Jefferson Hwy., New Orleans, LA 70121. Tel: (504) 842-3660. Email: eleanor.gradidge@ochsner.org

\section{INTRODUCTION}

In 1963, Reye et al first described a distinct clinicopathologic entity characterized by "disturbed consciousness, fever, convulsions, vomiting, disturbed respiratory rhythm, altered muscle tone, and altered reflexes" with an unknown cause. ${ }^{1}$ This rare and potentially fatal disease entity affecting multiple organ systems was later termed Reye syndrome. Various agents have been suggested as etiologies of Reye syndrome, including an intrinsic toxin causing disruption in the mitochondrial system, dysfunctional lipid and ammonia metabolism, an extrinsic toxin altering the patient's response to bacterial or viral prodrome, and genetic susceptibility. ${ }^{2}$ The only agent, however, that has been statistically proven to be a cause of Reye syndrome is aspirin (acetylsalicylic acid) intake during the viral prodromal phase in young children, a finding that led to issuance of a warning against aspirin administration to children in $1980 .{ }^{3}$ Since then, Reye syndrome incidence in the United States has declined sharply, although rare incidents have been reported from other etiologies. ${ }^{4}$ We describe a case of Reye syndrome from influenza $A$ virus in a 2-year-old male.

\section{CASE REPORT}

A 2-year-old male with no significant medical or family history presented to the emergency department (ED) after he was found unresponsive with vomitus in his mouth. He had influenza-like symptoms including cough, rhinorrhea, diarrhea, vomiting, and fatigue without fever 3 days prior to presentation. His parents gave him acetaminophen twice daily for symptom control. On initial physical examination in the ED, the patient had a Glasgow Coma Scale score of 8 and was somnolent but arousable, withdrawing to pain, perfusing well, spontaneously breathing, and had bilateral clonus. Pupils were equal size and constricted with light. Vital signs were normal for his age. Rapid viral testing was positive for influenza A virus. Significant laboratory results included anemia (hemoglobin $9.2 \mathrm{~g} / \mathrm{dL}$ ), hypernatremia (serum sodium $152 \mathrm{mmol} / \mathrm{L}$ ), transaminitis (aspartate aminotransferase $[\mathrm{AST}] 3,460 \mathrm{U} / \mathrm{L}$ and alanine aminotransferase [ALT] 1,956 U/L), hyperbilirubinemia (total bilirubin $2.4 \mathrm{mg} / \mathrm{dL}$, direct bilirubin $1.9 \mathrm{mg} / \mathrm{dL}$ ), elevated international normalized ratio (INR 4.7), hyperammonemia (serum ammonia $96 \mu \mathrm{mol} /$ $\mathrm{L})$, lactic acidosis (serum lactic acid $3.2 \mathrm{mmol} / \mathrm{L}$ ), azotemia (blood urea nitrogen $50 \mathrm{mg} / \mathrm{dL}$ ), hypercreatinemia (serum creatinine $0.92 \mathrm{mg} / \mathrm{dL}$ ), elevated creatine phosphokinase $(544 \mathrm{U} / \mathrm{L})$, elevated procalcitonin $(25.9 \mathrm{ng} / \mathrm{mL})$, elevated Creactive protein $(1.44 \mathrm{mg} / \mathrm{dL}$ ), and hypoglycemia (serum glucose $5 \mathrm{mg} / \mathrm{dL}$ ). Gamma-glutamyltransferase was normal $(12 \mathrm{U} / \mathrm{L})$; salicylate, ethanol, and urodynamic studies were negative. The patient was admitted to the hospital. His initial serum acetaminophen level of $30 \mathrm{mcg} / \mathrm{mL}$ had decreased to $8 \mathrm{mcg} / \mathrm{mL}$ at admission.

On day 1 of his hospitalization, the patient's liver function deteriorated; AST increased to $>20,000 \mathrm{U} / \mathrm{L}$, ALT to 9,509 U/L, and ammonia to $180 \mu \mathrm{mol} / \mathrm{L}$. Two days after admission, he was transferred to the pediatric intensive care unit for 


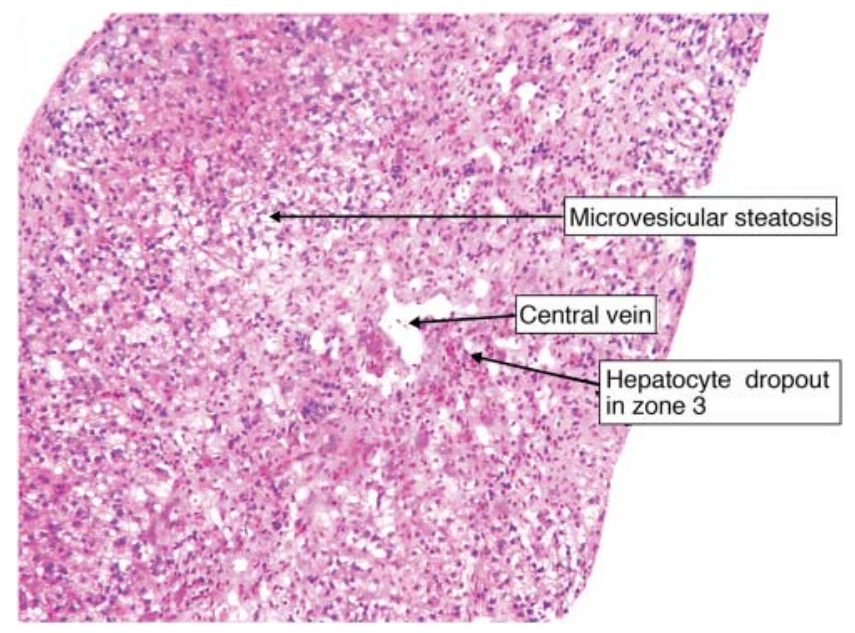

Figure 1. Prominent microvesicular steatosis with zone 3 hepatocyte dropout and paucity of inflammatory cells (magnification 20x).

hepatic failure. He became delirious, agitated, and combative and had unintelligible speech. He was intubated and placed on mechanical ventilation for grade 3 hepatic encephalopathy. All tests in an extensive diagnostic evaluation, including testing for autoimmune, inflammatory, infective, toxicologic, metabolic, hematologic, and oncologic etiologies, were negative. Urinalysis on the fourth day of admission revealed proteinuria (urine protein $100 \mathrm{mg} / \mathrm{dL}$ ) indicative of rhabdomyolysis, but the urine was negative for urobilinogen and nitrites.

Because of the patient's liver failure and positive result for influenza A, Reye syndrome was the leading differential. Liver biopsy revealed central hepatic venous collapse with surrounding microvesicular steatosis of the hepatocytes consistent with Reye syndrome (Figures 1 and 2).

In addition to supportive care, the patient was treated with lactulose every 6 hours and rifaximin $10 \mathrm{mg} / \mathrm{kg}$ twice daily to lower serum ammonia levels. This treatment continued for 8 days. The patient was extubated on day 7 . His liver function

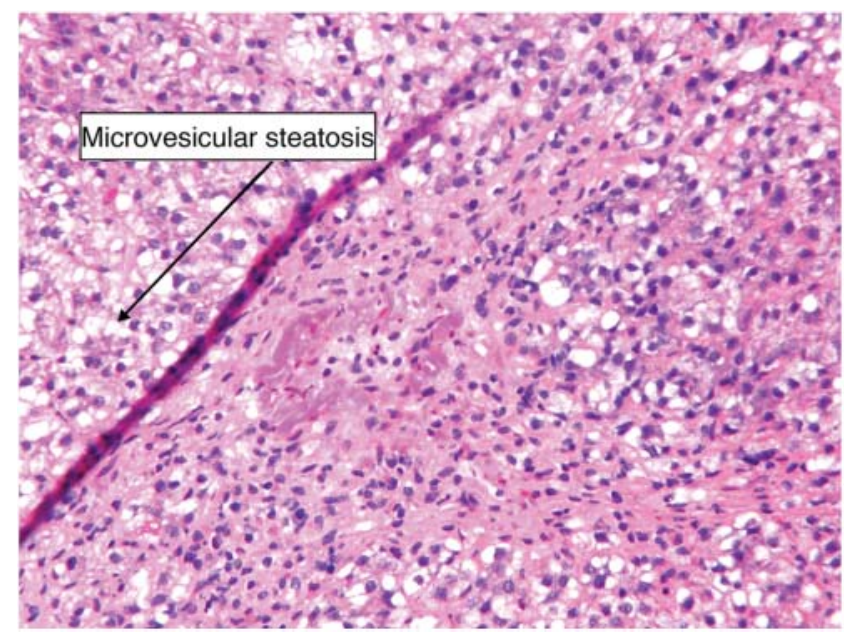

Figure 2. A closer look at microvesicular steatosis (magnification $40 \times$ ). gradually improved with supportive care, fresh frozen plas$\mathrm{ma}$, and vitamin $\mathrm{K} 10 \mathrm{mg} / \mathrm{kg}$ as needed. His liver enzymes trended down from AST 4,986 U/L and ALT 5,841 U/L on day 3 , to AST $421 \mathrm{U} / \mathrm{L}$ and $A L T 1,744 \mathrm{U} / \mathrm{L}$ on day 6 , and to AST $53 \mathrm{U} / \mathrm{L}$ and ALT $208 \mathrm{U} / \mathrm{L}$ on day 17 of his hospitalization. His INR trended down from 3.2 on day 2, to 1.9 on day 5 , and to 1.2 on day 10. He developed hypertension thought to be caused by acute kidney injury secondary to rhabdomyolysis. Maximum blood pressure was $169 / 98 \mathrm{mmHg}$ on day 14 , and he was treated with labetalol $2 \mathrm{mg} / \mathrm{kg} /$ day initially. He remained on labetalol through discharge with good response. His total duration of hospital stay was 17 days, and he was discharged home. On follow-up 4 months following discharge, the patient's guardians reported that he was achieving normal developmental milestones.

\section{DISCUSSION}

The Centers for Disease Control and Prevention defines Reye syndrome as an acute, noninflammatory encephalopathy characterized by alterations in the level of consciousness. ${ }^{5}$ The encephalopathy must be associated with either fatty changes of the liver or at least a 3-fold increase in the levels of ALT, AST, or serum ammonia with no other reasonable explanation for the hepatic and cerebral abnormalities. ${ }^{5}$

The National Reye Syndrome Surveillance System classifies Reye syndrome into 6 stages: ${ }^{4}$

- Stage 1 - Difficult to arouse, lethargy, sleepiness

- Stage 2 - Delirious, combative, disoriented with purposeful and semipurposeful movements

- Stage 3 - Coma, decorticate rigidity, with preservation of pupillary light and ocular reflexes

- Stage 4 - Deepened coma, decerebrate rigidity, loss of pupillary reflexes

- Stage 5 - Unarousable, flaccid paralysis, areflexia, and pupillary unresponsiveness to light

- Stage 6 - Treated with curare or other medications and therefore unclassifiable

Our patient met the criteria for stage 2 Reye syndrome with markedly elevated liver enzymes, fatty infiltration shown in the liver biopsy, disorientation, delirium, and combativeness without posturing. Influenza A virus is the suspected etiology for this patient's Reye syndrome, as an extensive evaluation was negative for other causes.

From December 1980 through November 1997, more than 1,200 cases of Reye syndrome were reported in the United States. ${ }^{4}$ The fatality rate of Reye syndrome has been $31 \%$, with the highest rate seen among children $<5$ years old. ${ }^{4}$ Since a warning was placed on aspirin in 1980 , no more than 36 new cases have occurred per year. ${ }^{4}$ Therefore, any incidence of the disease warrants investigation to identify possible etiologies as well as treatments to potentially reduce fatality. In our case, influenza A directly preceded the onset of disease course, and supportive care with careful monitoring led to functional recovery.

\section{CONCLUSION}

The incidence of Reye syndrome has decreased since the Centers for Disease Control and Prevention issued a warning against giving aspirin to children. Aspirin was not given to the patient in this case, but he still had a classic presentation 
of hepatic encephalopathy and met the clinical criteria for Reye syndrome. Although aspirin is the only statistically proven agent to cause Reye syndrome, our case adds to the evidence that other etiologies, including influenza $A$, can result in Reye syndrome.

\section{ACKNOWLEDGMENTS}

The authors have no financial or proprietary interest in the subject matter of this article. The authors would like to thank Caley Mclntyre, MD for his edits and valuable feedback and Mona Bansal, MD for providing the pathology images and guidance in their interpretation.

\section{REFERENCES}

1. Reye RD, Morgan G, Baral J. Encephalopathy and fatty degeneration of the viscera. A disease entity in childhood. Lancet. 1963 Oct 12;2(7311):749-752.
2. Maheady DC. Reye's syndrome: review and update. J Pediatr Health Care. 1989 Sep-Oct;3(5):246-250.

3. Centers for Disease Control. Follow-up on Reye's syndrome United States. MMWR Morb Mortal Wkly Rep. 1980;29: 321-322.

4. Belay ED, Bresee JS, Holman RC, Khan AS, Shahriari A, Schonberger LB. Reye's syndrome in the United States from 1981 through 1997. N Engl J Med. 1999 May 6;340(18): 1377-1382.

5. Reye syndrome. 1990 case definition. Centers for Disease Control and Prevention. wwwn.cdc.gov/nndss/conditions/ reye-syndrome/case-definition/1990/. Accessed August 13, 2018.

This article meets the Accreditation Council for Graduate Medical Education and the American Board of Medical Specialties Maintenance of Certification competencies for Patient Care and Medical Knowledge. 